\title{
Characterisation of glucose transporters in the intact coronary artery endothelium in rats: GLUT-2 upregulated by long-term hyperglycaemia
}

\author{
N. Gaudreault ${ }^{1}$ D. R. L. Scriven ${ }^{1}$ - E. D. W. Moore ${ }^{1}$ \\ ${ }^{1}$ Department of Physiology, University of British Columbia, Vancouver, B.C., Canada
}

\begin{abstract}
Aims/hypothesis. We have examined the effects of streptozotocin-induced type 1 diabetes on the expression and subcellular distribution of the classic sugar transporters (GLUT-1 to 5 and sodium-dependent glucose transporter-1 [SGLT-1]) in the endothelial cells of an en face preparation of septal coronary artery from Wistar rats.

Methods. The presence of the GLUT isoforms and SGLT-1 in the endothelial cell layer was determined by immunohistochemistry using wide-field fluorescence microscopy coupled to deconvolution, and was quantified by digital image analysis.

Results. We found that all of the transporters were expressed within these cells and that all except SGLT-1 were preferentially located on the abluminal side. The heaviest labelling was adjacent to the cell-to-cell junc-
\end{abstract}

tions where the luminal and abluminal membranes are in close proximity, which may reflect a spatial organisation specialised for vectorial glucose transport across the thinnest part of the cytoplasm. Long-term hyperglycaemia, induced by streptozotocin, significantly downregulated GLUT-1, 3, 4 and 5 and dramatically upregulated GLUT-2, leaving SGLT-1 unchanged.

Conclusions/interpretation. We conclude that the high susceptibility of endothelial cells to glucose toxicity may be the result of the subcellular organisation of their GLUTs and the increased expression of GLUT-2.

Keywords Deconvolution - Digital image analysis . Endothelial cells · Fluorescence microscopy · Glucose toxicity · GLUT · Hyperglycaemia - SGLT ·

Streptozotocin.
Received: 26 April 2004 / Accepted: 18 July 2004

Published online: 10 December 2004

(C) Springer-Verlag 2004

E. D. W. Moore (匹)

Department of Physiology, University of British Columbia, 2146 Health Sciences Mall, Vancouver, B.C., V6T 1Z3, Canada

E-mail: edmoore@interchange.ubc.ca

Tel.: +1-604-8223423, Fax: +1-604-8226048

Abbreviations: DAPI, 4',6-diamidino-2-phenylindole dihydrochloride $\cdot$ Dil-Ac-LDL, acetylated LDL labelled with 1,1'-dioctadecyl-3,3,3',3'-tetramethylindo-carbocyanine perchlorate $\cdot$ FITC, fluorescein isothiocyanate $\cdot 12$-HETE, 12-hydroxyeicosatetraenoic acid - PARP, pdy ADP-ribose polymerase - SGLT, sodium-dependent glucose transporter . STZ, streptozotocin - TBS-T, Tris-buffered saline Tween · VE, vascular endothelial

\section{Introduction}

The endothelium is the first line of protection for the vascular wall as it occupies a strategic position between the blood and the underlying tissue. The role and function of endothelial cells varies between vascular beds: in capillaries, endothelial cells regulate gas and nutrient exchange or prevent the passage of harmful substances; while in larger vessels they also control vascular tone by releasing vasoconstrictors and vasodilators [1]. In small contractile vessels deprived of the vasa vasorum (small blood vessels irrigating the walls of large blood vessels), such as coronary arteries, the endothelial cells must allow transport between the blood and the cells of the vascular wall, but they must also protect the vessel's integrity through selective permeability. Elucidating the processes by 
which endothelial cells mediate the exchange of plasma molecules through the vascular wall while at the same time safeguarding its functional integrity is important for understanding how endothelial cell dysfunction relates to systemic diseases such as diabetes, in which the main causes of morbidity and mortality are vascular diseases [2].

Hyperglycaemia has long been associated with impaired endothelial function [3]. Most studies have focused on the mechanism by which elevated intracellular glucose induces endothelial dysfunction $[4,5]$. It is only recently that the regulation of glucose transport in endothelial cells has been examined [6], and most of this work has been on the blood-brain and blood-retina barriers [7, 8, 9]. The integrity of endothelial cells of small contractile vessels is also affected by hyperglycaemia, and the coronary arteries are among the most susceptible to atheroma, but few studies have directly examined glucose transporters in these vessels [6]. Despite having the same embryonic origin, there is a strong heterogeneity between endothelial cells of different vascular beds, and even those within the same vascular bed are known to have morphological, physiological and biochemical differences $[10,11]$. Data derived from one vascular bed may not be applicable to the rest of the vasculature.

In this study, we examined the expression and subcellular distribution of the classic GLUTs (1-5) and sodium-dependent glucose transporter (SGLT)-1 in en face preparations of rat coronary artery endothelia. Given the susceptibility of the endothelial cell to hyperglycaemia, we hypothesised that the expression and subcellular distribution of the transporters would favour intracellular glucose accumulation, and that there would be an inappropriate adaptation to the diabetic state.

\section{Materials and methods}

All chemicals were purchased from Sigma-Aldrich (Oakville, Ont, Canada) unless otherwise stated. Animal handling was done in accordance with the guidelines of the Canadian Council on Animal Care and the Principles of Laboratory Animal Care (NIH publication no. 85-23, revised 1985).

Animals. Male Wistar rats (200-235 g; University of British Columbia Animal Care Centre, Vancouver, BC, Canada) were given streptozotocin (STZ; $50 \mathrm{mg} / \mathrm{kg}$, dissolved in saline) or saline $(1 \mathrm{ml} / 100 \mathrm{~g})$ via injection through the tail-vein. Animals were killed 8 weeks later with a peritoneal injection of pentobarbital $(0.1 \mathrm{ml} / 100 \mathrm{~g})$. During this period, biweekly morning measurements of tail-vein blood glucose were carried out (One Touch II glucometer; Lifescan Canada, Burnaby, BC, Canada) and body weight was recorded.

Tissue preparation. The septal coronary artery (about $250 \mu \mathrm{m}$ in diameter) was dissected from the surrounding tissue in segments of approximately $1.0 \mathrm{~mm}$ in length. The tissue was immersed in ice-cold oxygenated $\left(95 \% \mathrm{O}_{2} / 5 \% \mathrm{CO}_{2}\right)$ Krebs buffer solution (in mmol/l: $119 \mathrm{NaCl}, 4.7 \mathrm{KCl}, 1.18 \mathrm{KH}_{2} \mathrm{PO}_{4}, 1.17$
$\mathrm{MgSO}_{4}, 24.9 \mathrm{NaCO}_{3}, 11.1$ dextrose, $2.5 \mathrm{CaCl}_{2} ; \mathrm{pH}$ 7.4) during the dissection.

The vessel was cut longitudinally to expose the luminal side of the vessel, avoiding damage to the endothelium, and was then fixed in $2 \%$ paraformaldehyde dissolved in PBS (in mmol/l: $137 \mathrm{NaCl}, 8 \mathrm{NaH}_{2} \mathrm{PO}_{4}, 2.7 \mathrm{KCl}, 1.5 \mathrm{KH}_{2} \mathrm{PO}_{4}$; $\mathrm{pH} 7.4$ ) for $10 \mathrm{~min}$, a method previously described by Dan et al. [12]. Fixation was quenched with a $10-\mathrm{min}$ rinse in $100 \mathrm{mmol} / \mathrm{l}$ glycine (pH 7.4) and the cells were permeabilised with $0.06 \%$ saponin in PBS for $10 \mathrm{~min}$ at room temperature followed by three 10-min rinses with PBS.

Immunostaining. Non-specific binding sites were blocked by incubating the fixed, permeabilised tissue in $10 \%$ donkey serum dissolved in PBS for $2 \mathrm{~h}$ at room temperature. Vessels were then incubated overnight at $4{ }^{\circ} \mathrm{C}$ with two antibodies raised in different species: one against a glucose transporter isoform (GLUT-1 to 5 or SGLT-1), and one against an endothelial cell or membrane marker (vascular endothelial [VE]-cadherin, von Willebrand factor, or caveolin-1). The optimal antibody concentrations were determined empirically. All antibodies were diluted in antibody buffer (in mmol/l: $75 \mathrm{NaCl}$, $18 \mathrm{Na}_{3}$ citrate with $2 \%$ donkey serum, $1 \%$ bovine serum albumin, $0.06 \%$ saponin, and $0.02 \% \mathrm{NaN}_{3}$ ). The antibody sources, concentrations, epitopes and suppliers are listed in Table 1.

Excess antibody was removed by three 10-min rinses in antibody wash solution (in mmol/l: $75 \mathrm{NaCl}, 18 \mathrm{Na}_{3}$ citrate with $0.06 \%$ saponin). The tissue was then incubated for $2 \mathrm{~h}$ with two donkey affinity-purified secondary antibodies that had been solid-phase absorbed to minimise species cross-reactivity (Jackson ImmunoResearch Laboratories, West Grove, Pa., USA). The secondary antibodies were conjugated to either fluorescein isothiocyanate (FITC) or Texas Red and diluted in antibody buffer. Following incubation with the secondary antibodies, the tissue was rinsed three times for $10 \mathrm{~min}$ in antibody wash solution. The nuclei of the cells were then labelled with 4',6-diamidino-2-phenylindole dihydrochloride (DAPI; $0.3 \mu \mathrm{mol} / 1$; Molecular Probes, Eugene, Ore., USA) for $5 \mathrm{~min}$ and rinsed three times for $10 \mathrm{~min}$ in PBS. The labelled vessels were mounted on a coverslip in DABCO mounting medium (90\% glycerol, $10 \%$ 10× PBS, $2.5 \%$ triethylenediamine, and $0.02 \% \mathrm{NaN}_{3}$ ). To avoid compression of the vessel, the edges of the coverslips were suspended on a thin layer of clear nail polish that had been applied to the slide. Small subresolution beads were added to the DABCO (TetraSpeck Fluorescent microsphere standards, $0.22 \mu \mathrm{m}$ diameter; Molecular Probes). These fluoresce at all the wavelengths used (DAPI, FITC and Texas Red) and enabled alignment of the data sets.

Two control experiments were conducted. In the first, vessels were labelled with a primary antibody and an inappropriately targeted secondary antibody. In the second, the primary antibody was omitted.

The adherens junctions, of which VE-cadherin is an integral part, separate the luminal from the abluminal side of the cell $[13,14]$. We used the position of this molecule to optically dissect the cells into luminal and abluminal sides. This was not possible for the GLUT-3 transporter, for which the antibody was also raised in goats. In this case, we used mouse anti-von Willebrand factor to mark the endothelial cells, and used the contact points of neighbouring cells to demarcate the luminal-abluminal boundary [15].

Acetylated LDL uptake. Arteries were dissected in Krebs solution as described above and were cut longitudinally to expose the endothelial cells. The arteries were then incubated for $4 \mathrm{~h}$ at $37{ }^{\circ} \mathrm{C}$ in an incubator equilibrated with $5 \% \mathrm{CO}_{2}$, immersed in culture medium (Gibco RPMI medium 1640; Invitrogen, 
Table 1. List of the primary antibodies concentrations epitopes and suppliers

\begin{tabular}{|c|c|c|c|c|}
\hline Primary antibody & $\begin{array}{l}\text { Immunohisto- } \\
\text { chemistry } \\
(\mu \mathrm{g} / \mathrm{ml})\end{array}$ & $\begin{array}{l}\text { Western } \\
\text { blotting } \\
(\mu \mathrm{g} / \mathrm{ml})\end{array}$ & Epitope & Supplier \\
\hline Goat human VE-cadherin (C-19) (poly IgG) & 6.6 & - & \multirow[t]{2}{*}{$\begin{array}{l}\text { Intracellular domain } \\
\text { carboxy terminus }\end{array}$} & $\begin{array}{l}\text { Santa Cruz Biotechnology, } \\
\text { Santa Cruz, Calif, USA }\end{array}$ \\
\hline Mouse caveolin-1 (mono IgM) & 80 & - & & $\begin{array}{l}\text { Transduction Laboratories, } \\
\text { Lexington, Ky, USA }\end{array}$ \\
\hline Rabbit GLUT-2 (neat serum) & $\begin{array}{l}\text { Dilution } \\
1: 500^{\mathrm{a}}\end{array}$ & $\begin{array}{l}\text { Dilution } \\
1: 500^{\mathrm{a}}\end{array}$ & $\begin{array}{l}\text { Intracellular domain } \\
\text { carboxy terminus } \\
25 \text { aa }\end{array}$ & $\begin{array}{l}\text { East Acres Biologicals, } \\
\text { Southbridge, Mass, USA }\end{array}$ \\
\hline Goat GLUT-3 (M-20) (poly IgG) & 10 & 0.8 & $\begin{array}{l}\text { Intracellular domain } \\
\text { carboxy terminus }\end{array}$ & $\begin{array}{l}\text { Santa Cruz Biotechnology, } \\
\text { Santa Cruz, Calif, USA }\end{array}$ \\
\hline Rabbit SGLT-1 (poly IgG) & 10 & - & $\begin{array}{l}\text { Extracellular domain } \\
\text { aa } 402-420\end{array}$ & $\begin{array}{l}\text { Alpha Diagnostic, } \\
\text { San Antonio, Tex, USA }\end{array}$ \\
\hline
\end{tabular}

a Exact antibody concentration not determined. VE, vascular endothelial

Burlington, Ont, Canada) to which the following were added: $1 \%$ serum replacement and $10 \mu \mathrm{g} / \mathrm{ml}$ of acetylated LDL labelled with $1,1^{\prime}$-dioctadecyl-3,3,3',3'-tetramethylindo-carbocyanine perchlorate (Dil-Ac-LDL; Biomedical Technologies, Mass., USA). After a 10-min wash in fresh media, without Dil-Ac-LDL, the artery was incubated for 5 min with a nucleic acid stain (Hoechst 33342, trihydrochloride, trihydrate; $200 \mu \mathrm{g} / \mathrm{ml}$; Molecular Probes). The vessel was washed for $10 \mathrm{~min}$ in fresh medium, mounted open on a coverslip in fresh medium, which was sealed to the slide with clear nail polish, and then imaged immediately.

Western blots. Tissue lysate and homogenate were obtained from rat septal coronary artery, epididymal adipose tissue, heart ventricle, jejunum, and brain cortex. After dissection, the arteries were longitudinally opened as described above. This procedure exposes, primarily, the endothelium to the lysis buffer (0.025 mol/l PBS [pH 7.4], $150 \mathrm{mmol} / \mathrm{l} \mathrm{NaCl}$, $2.5 \mathrm{mmol} / \mathrm{l}$ EDTA, $0.5 \%$ ethoxylate octyl phenol, $10 \%$ glycerol) in which the tissue was incubated for $30 \mathrm{~min}$ on ice. All other tissues were dissected and homogenised, in the same icecold lysis buffer, using two 20-s pulses of a Polytron (type PT 10 OD; Kinematica, Lucerne, Switzerland) at medium to high speed. They were then incubated on ice for $30 \mathrm{~min}$. The homogenised tissues were centrifuged at $4{ }^{\circ} \mathrm{C}$ for $10 \mathrm{~min}$ at 1000 $g$ to remove any cellular debris. Protein concentrations were determined using a modified Lowry reagent protein assay kit (Pierce, Rockford, Ill., USA). Two parts of tissue lysate or homogenate were combined with one part of sample buffer $(3 x$ concentrate, $0.175 \mathrm{~mol} / 1$ Tris, $44 \%$ glycerol, $15 \% \beta$-2-mercapto-ethanol, $7 \%$ SDS, $0.01 \%$ Bromophenol Blue; pH 6.8) and boiled for $5 \mathrm{~min}$ (GLUT-2 gave better results with the omission of the boiling step). Tissue samples and the prestained protein ladder (unboiled; Fermentas, Burlington, Ont, Canada) were loaded and resolved on a 5\% stacking and $12.5 \%$ running SDS-PAGE, and the proteins were transferred to the nitrocellulose membrane. Antibody incubations with the membranes were performed at $37{ }^{\circ} \mathrm{C}$ with gentle agitation. Non-specific binding sites were blocked with $10 \%$ non-fat dry milk in Trisbuffered saline Tween (TBS-T; $50 \mathrm{mmol} / \mathrm{l}$ Tris, $0.09 \% \mathrm{NaCl}$, and $0.01 \%$ Tween; $\mathrm{pH}$ 7.6). The membranes were then incubated with primary antibodies diluted in 5\% non-fat dry milk in TBS-T, rinsed with TBS-T and further incubated with the appropriate horseradish peroxidase-conjugated secondary antibodies (1:20,000, either anti-mouse, anti-rabbit or anti-goat; Jackson ImmunoResearch Laboratories) also diluted in 5\% non-fat dry milk in TBS-T. After a final rinse in TBS-T, the membranes were treated with a Western Lightning Chemiluminescence Reagent Plus detection system (Perkin Elmer Life Sciences, Boston, Mass., USA) and developed on Kodak BioMax film (Amersham Biosciences, Baie D'Urfe, Que, Canada). Control experiments were performed without the primary antibodies and demonstrated the specificity of the labelled single band for each protein probed (data not shown).

A BLAST search (National Center for Biotechnology Information, Washington, D.C., USA) was conducted to ensure that the antibodies used in this study only targeted the proteins of interest.

Immunohistochemistry. Antibody specificity was also tested by labelling tissues in which the glucose transporters had been previously characterised $[16,17,18]$. As positive and negative immunostaining controls, red blood cells, pancreatic islets, neuronal primary culture, epididymal adipose tissue and segments of the jejunum were labelled with antibodies against GLUT-1, 2, 3, 4 and 5 and SGLT-1. Blood samples were collected from rat tail-vein, heparinised $(10 \%)$ and centrifuged for $5 \mathrm{~min}$ at $17,000 \mathrm{~g}$. The plasma was removed and the erythrocytes fixed and labelled as described above. Whole pancreas, epididymal adipose tissue and segments of the jejunum were dissected from rats in Krebs solution, embedded in Tissue Tek (Sakura, Torrance, Calif., USA) and flash frozen in liquidnitrogen-cooled isopentane at $-60{ }^{\circ} \mathrm{C}$. Cross-sections of these tissues were cut on a cryostat, thaw-mounted on Superfrost 
slides (VWR, Edmonton, Alta, Canada), fixed, and labelled as described above. Primary cultures of rat neurons were obtained from K. Baimbridge (Department of Physiology, University of British Columbia, Vancouver, BC, Canada) [19, 20]. The neurons were fixed, and then labelled as described above.

3D image acquisition, deconvolution and analysis. A series of two-dimensional fluorescent images was acquired through the depth of the cell using a standard Nikon Diaphot 200 inverted microscope equipped for epifluorescence (100 W Hg illumination, $60 \times$ oil immersion objective, NA $1.4,4 \times$ adaptor). The pixel size was $100 \times 100 \mathrm{~nm}$ and the $Z$ spacing was $250 \mathrm{~nm}$. Images were recorded with a thermoelectrically cooled chargecoupled device camera with an SITe SI502AB chip, peak quantum efficiency of $80 \%$, and 16-bit dynamic range (Photometrics, Tucson, Ariz., USA). For each wavelength, a threedimensional data set was acquired using narrow bandpass filters specific for FITC, Texas Red and DAPI (XF22, XF43, XF06; Omega Optical, Brattleboro, Vt., USA). Images were background and dark current subtracted and corrected for photobleaching as previously described [21]. A flat field was used to correct for non-uniform illumination and camera sensitivity across the field of view. Images were deconvolved using the algorithm developed by Carrington et al. [22], with an empirically determined point spread function on an exhaustive photon reassignment client server (Scanalytics, Billerica, Mass., USA). Small fluorescent microspheres (100 nm diameter; Molecular Probes) of the appropriate wavelength were used to measure the point spread function of the microscope. After deconvolution, each image was thresholded by partitioning the image grey-scale histogram based on visual inspection of the image and its histogram. The background was segmented from the image by assigning a zero value to all pixels with a grey level lower than the threshold. Deconvolved and thresholded images were aligned using the fiduciary markers. All images are $3 \mathrm{D}$ reconstructions of the indicated depth.

Data quantification and statistical analysis. Images of single cells were digitally isolated from the image of the endothelial layer. The distribution of the GLUTs and SGLT was quantified by dividing each $3 \mathrm{D}$ image into a series of non-overlapping 5 - $\mu$ m-thick segments along their long axis. Each segment was then divided into a luminal and abluminal section using VE-cadherin and neighbouring cells as guides, and the number of labelled voxels on both sides was counted. The total number of labelled voxels on each side was summed over the volume of the entire cell and expressed as a ratio of the number of abluminal : luminal voxels. The data are presented as means $\pm \mathrm{SE}$ and compared using ANOVA with orthogonal contrasts as required.

\section{Results}

Weight and blood glucose. The mean weights and morning blood glucose concentrations of the control Wistar rats at the time they were killed were $493 \pm 10 \mathrm{~g}$ and $3.90 \pm 0.03 \mathrm{mmol} / \mathrm{l}$ respectively $(n=5)$. STZ-diabetic rats $(n=8)$ had a significantly lower mean weight at the time they were killed than the control animals $(367 \pm 11 \mathrm{~g}, p<0.05)$ and significantly elevated morning blood glucose concentrations $(18.90 \pm 0.72 \mathrm{mmol} / \mathrm{l}$, $p<0.05)$. Daily weight and morning blood glucose measurements confirmed that the diabetic state of the
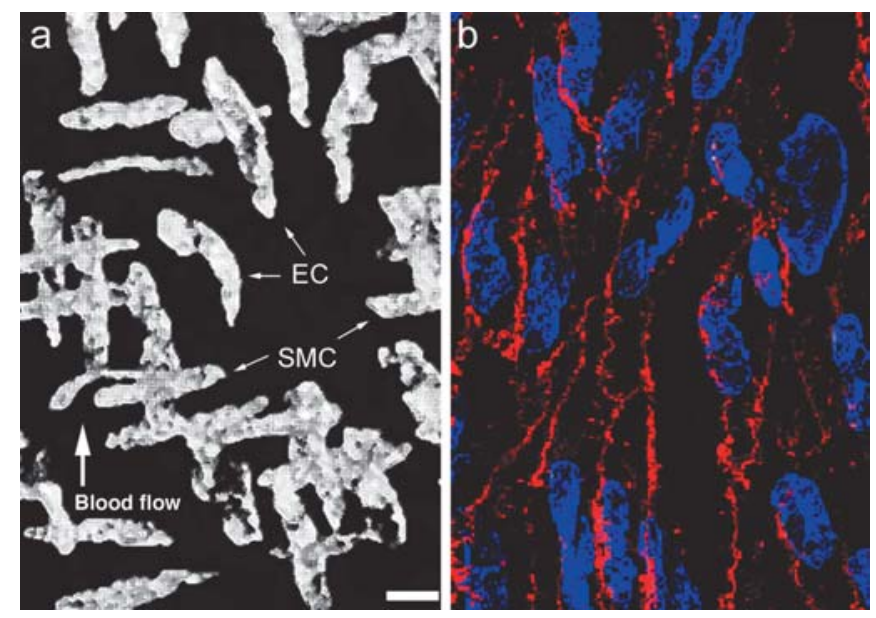

Fig. 1. Identification of endothelial cells in deconvolved images of en face septal coronary artery (3D reconstruction, view of the cells from the lumen). a. Smooth muscle cell (SMC) and endothelial cell (EC) nuclei are indicated. The image is $10 \mu \mathrm{m}$ deep. b. VE-cadherin (red) and nuclei (blue). The image is $1.25 \mu \mathrm{m}$ deep. Scale bar is $8 \mu \mathrm{m}$

STZ-injected rats was sustained throughout the experiment.

Identification of endothelial cells. Endothelial cells were distinguished from other cells of the vascular wall using morphological criteria and specific markers. The nuclei of endothelial cells are oriented parallel to the lumen due to the shear stress produced by blood flow [23], whereas smooth muscle cell nuclei are oriented perpendicularly. This is reflected in the fusiform shape of the DAPI-labelled nuclei and in their orientation, parallel to the long axis of the vessel, as shown in Fig. 1a.

In addition, endothelial cells were identified by immunolabelling with two different endothelial cell markers: VE-cadherin (Fig. 1b) and von Willebrand factor (used with GLUT-3 labelling; not shown). Both antibodies react positively with the top monolayer of the vascular wall where labelled nuclei run parallel to the lumen.

To determine whether the endothelium was well preserved during the dissection procedures, cell viability was tested by visualising Ac-LDL uptake [24]. Fluorescence was observed in all cells of the top layer of freshly dissected vessels incubated with Ac-LDL for $4 \mathrm{~h}$. This demonstrates that the endothelial cells were intact and viable immediately prior to being fixed (data not shown).

Antibody specificity. Antibody specificity was first tested using western blots. Positive controls (fat, heart, brain and jejunum lysates) were used to establish the molecular weight band identified by the different antibodies. Single bands for GLUT-1 $\left(\sim 62 \mathrm{M}_{\mathrm{r}}\right)$, GLUT-2 $\left(\sim 72 \quad \mathrm{M}_{\mathrm{r}}\right)$, GLUT-3 $\left(\sim 47 \mathrm{M}_{\mathrm{r}}\right)$, GLUT-4 $\left(\sim 47 \mathrm{M}_{\mathrm{r}}\right)$ and GLUT-5 $\left(\sim 55 \mathrm{M}_{\mathrm{r}}\right)$ were found from en 
face septal coronary artery lysate (Fig. 2). The SGLT1 antibody did not recognise denatured protein and we were unable to produce a western blot for this antibody.

Due to their similarity in molecular weight, the western blot could not determine the isoform specificity of the antibodies utilised. We therefore used protocols established by others, and labelled cells and subcellular structures for which the glucose transporters had been well characterised: erythrocytes, pancreatic islets, neurons, adipose tissue and epithelial cells of the jejunum [16, 17, 18]. GLUT-1 (Fig. 3a), GLUT-2 (Fig. 3b) and GLUT-5 (Fig. 3e) were found in erythrocytes. The side view of the images (see insets) demonstrates the characteristic biconcave shape of the cell, indicating that the label was predominantly on the membrane. GLUT-3 (Fig. 3c), GLUT-4 (Fig. 3d) and SGLT-1 (Fig. 3f) were absent, consistent with previous studies [16]. Cross-sections of pancreatic islets showed the presence of GLUT-2 (Fig. 3h) but not GLUT-1 (Fig. 3g), in accordance with earlier data [17]. We also show positive controls for GLUT-3 labelling in neurons (Fig. 3i) and GLUT-4 labelling in adipocytes (Fig. 3j), as shown by other authors [25]. Lastly, we looked at the distribution of GLUT-2, GLUT-5 and SGLT-1 in epithelial cells of the jejunum, a tissue for which the glucose transporter organisation is well established [18]. Our results show a mostly basolateral distribution for GLUT-2 (Fig. 3k), GLUT-5 present on both the apical and basolateral membranes (Fig. 31) and an apical distribution for SGLT-1 (Fig. 3m), confirming published results [26].

No immunostaining was observed when secondary antibodies alone were applied to any of the preparations or when primary antibodies were applied in combination with a secondary antibody targeting an irrelevant species (data not shown). In addition, competitive blocking peptides for GLUT-3, GLUT-5 and SGLT-1 were tested. In all cases the immunoreactivity of the antibody was completely abolished when incubated with $5 \times$ (GLUT-3) or 10x (GLUT-5 and SGLT) excess of blocking peptides (data not shown).

Immunolocalisation. The relative distributions of GLUT-1 (green), VE-cadherin (red), and the nucleus (blue) in a coronary artery endothelial cell is displayed in Fig. 4a. The adherens junctions, as labelled by VEcadherin, are discontinuous, as expected for an endothelium experiencing shear stress [27]. The transporters were distributed in discrete clusters, mostly around the periphery of the nucleus and close to the edge of the cell. From the side view (Fig. 4b), it can be seen that the bulk of the nucleus was on the abluminal side of the cell, and that clusters of GLUT-1 were located on both the luminal and abluminal sides. Additional details were observed by rotating the image presented in Fig. $4 \mathrm{a}$ by $90^{\circ}$ about the $\mathrm{X}$ axis and extracting three $0.5-\mu \mathrm{m}$-thick cross-sections from the a

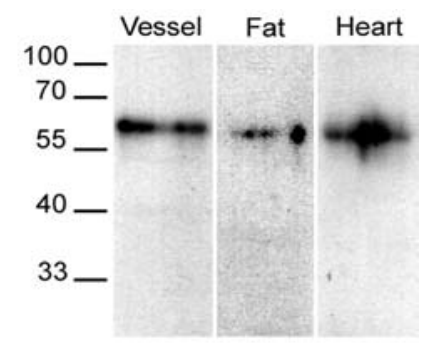

b

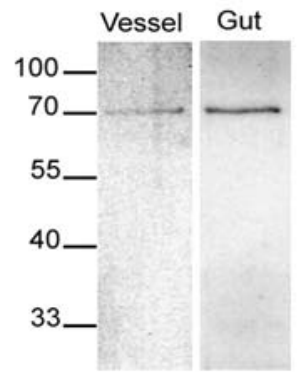

c

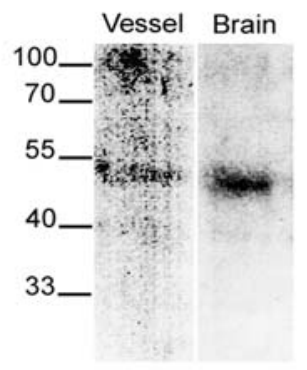

d

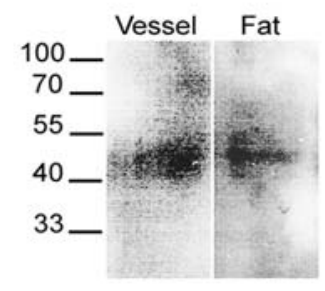

e

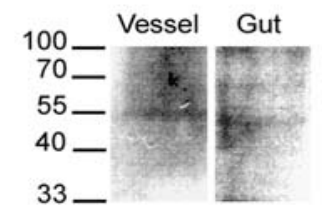

Fig. 2. Determination of antibody specificity with western blots. Rat tissue lysates from septal coronary artery blood vessel, epididymal adipose tissue, heart, jejunum and brain cortex. $30 \mu \mathrm{g}(\mathbf{a}-\mathbf{c})$ or $45 \mu \mathrm{g}(\mathbf{d}, \mathbf{e})$ of protein were separated by $12 \%$ SDS-PAGE. After transfer of the proteins to nitrocellulose, detection was performed using antibodies against (a) GLUT-1, (b) GLUT-2, (c) GLUT-3, (d) GLUT-4, and (e) GLUT-5. The position of $\mathrm{M}_{\mathrm{r}}$ markers is indicated on the left-hand side

indicated locations (Fig. 4c-e). These cross-sections demonstrated that GLUT-1 was located in the same region of the cell as VE-cadherin, and that when split into luminal and abluminal segments using VE-cadherin as a guide (Fig. 4f, g), the majority of the transporters appeared to be on the abluminal side. 

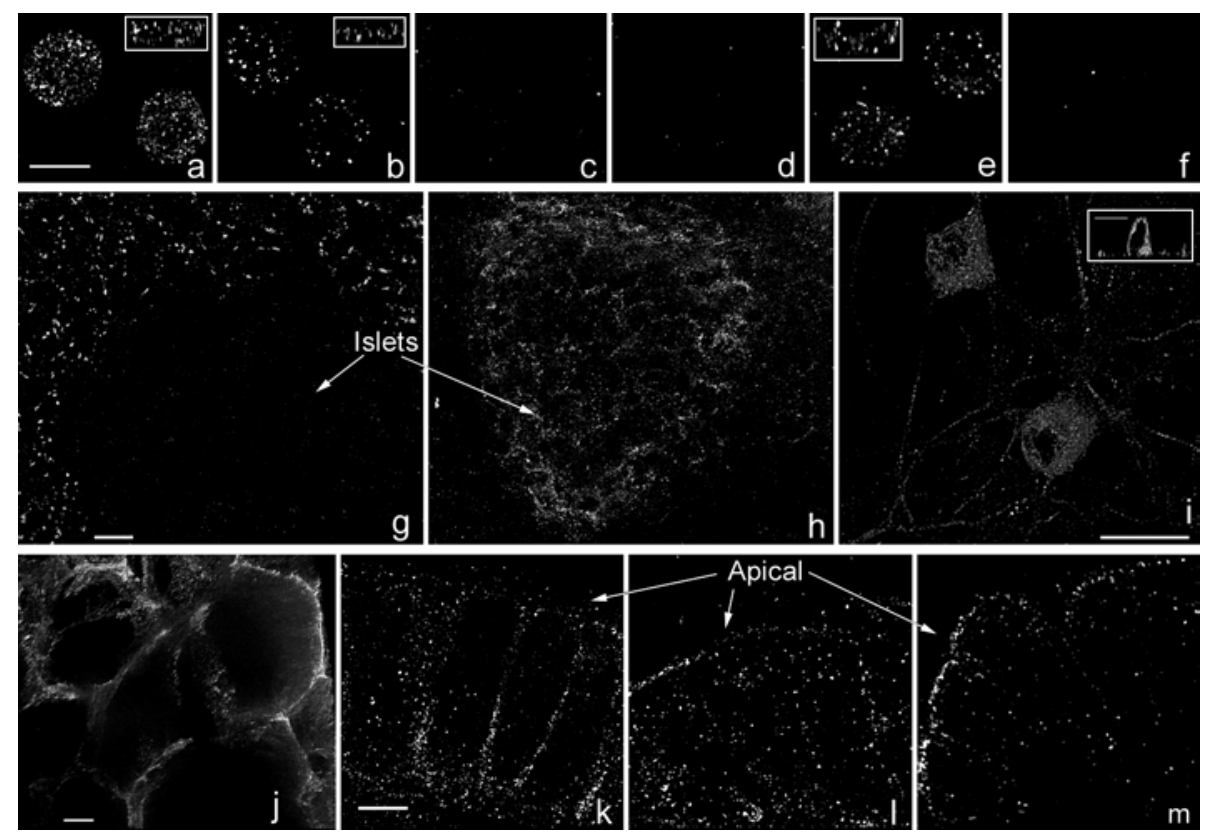

Fig. 3. Immunohistochemistry demonstrating antibody specificity. All images were deconvolved and represent a 3D reconstruction of whole cells or a section of cells or tissues from rats. a-f. Erythrocytes (3.75 $\mu \mathrm{m}$ deep), scale bar $5 \mu \mathrm{m}$, stained for (a) GLUT-1, (b) GLUT-2, (c) GLUT-3, (d) GLUT-4, (e) GLUT-5, and (f) SGLT-1. The insets in $\mathbf{a}, \mathbf{b}$ and $\mathbf{e}$ are crosssections (average of $2.5 \mu \mathrm{m}$ deep) of a side view of the erythrocytes. g, h. Cross-sections of pancreatic islet $(0.75 \mu \mathrm{m}$ deep),

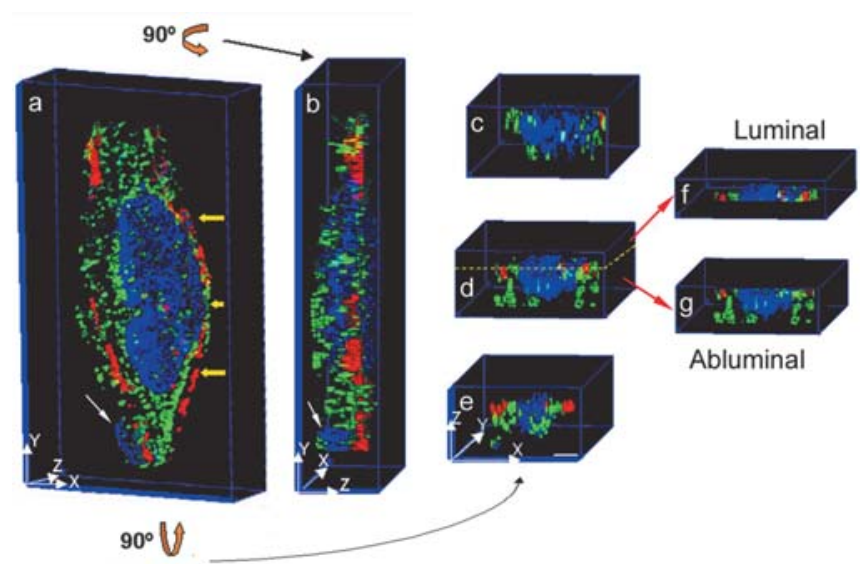

Fig. 4. Endothelial cell labelled with antibodies specific for GLUT-1 (green) and VE-cadherin (red), and with DAPI (blue). Scale bar is $2 \mu \mathrm{m}$ in each direction. a. $3 \mathrm{D}$ reconstruction, view of the cells from the lumen. The white arrow indicates a small section of an adjacent cell. b. Side view obtained from a $90^{\circ}$ rotation about the $\mathrm{Y}$ axis, luminal surface on the right. c-e. Half-micron-thick cross-sections were obtained from a at the points indicated by the yellow arrows, then rotated $90^{\circ}$ about the $\mathrm{X}$ axis, luminal surface on top. The yellow dashed line in $\mathbf{d}$ indicates where this cell segment was divided into luminal (f) and abluminal (g) sections. White pixels indicate colocalisation between VE-cadherin and GLUT-1 (a, b), or between GLUT-1 and DAPI (c, d, g) scale bar $20 \mu \mathrm{m}$, stained for (g) GLUT-1 and (h) GLUT-2. i. Neuronal primary culture labelled with GLUT-3. The image is $8 \mu \mathrm{m}$ deep and the scale bar is $20 \mu \mathrm{m}$. The inset is a crosssection of a side view of the neuron body. $\mathbf{j}$. Cross-section of epididymal adipose tissue (10 $\mu \mathrm{m}$ deep) labelled with GLUT-4. Scale bar is $20 \mu \mathrm{m}$. $\mathbf{k}-\mathbf{m}$. Jejunum epithelial cell cross-sections $(0.5 \mu \mathrm{m}$ deep, apical surface facing up) stained for (k) GLUT2, (l) GLUT-5, and (m) SGLT-1. Scale bar is $5 \mu \mathrm{m}$

The quantification of this distribution is presented in Fig. 5 and expressed as the mean ratio per cell and its SE. The ratio of abluminal : luminal voxels containing GLUT-1 in the cell shown was 10.6, and in a total of seven coronary artery endothelial cells examined, the abluminal : luminal ratio was $8.9 \pm 1.4$ (mean $\pm \mathrm{SE}$ ), implying that the majority of GLUT-1 was on the abluminal side.

Cross-sections (comparable to Fig. 4c-e) of images of endothelial cells labelled for GLUT-2, 3, 4, 5 and SGLT-1 are shown in Fig. 6. The distributions were similar to the distribution of GLUT-1: the transporters were distributed in discrete clusters present on both sides of the cell, and had a high density in proximity to the cell-to-cell junctions.

The quantitative differences between the transporters are highlighted in Fig. 5. An ANOVA of the mean abluminal : luminal ratios was significant $(p<0.001)$ and orthogonal contrasts indicated that the distributions fell into three different groups. SGLT-1 had an abluminal : luminal ratio that was not significantly different from 1 , and was therefore symmetrically distributed. GLUT-2, 3,4 and 5 had greater concentrations on the abluminal side with ratios that ranged from 2.1 to 3.5 , and were not significantly different from each other but were significantly different from both SGLT-1 and GLUT-1. GLUT-1 had the most asymmetric distribution with a ratio of 8.9 , which was significantly different from the other transporters $(p<0.01)$. 


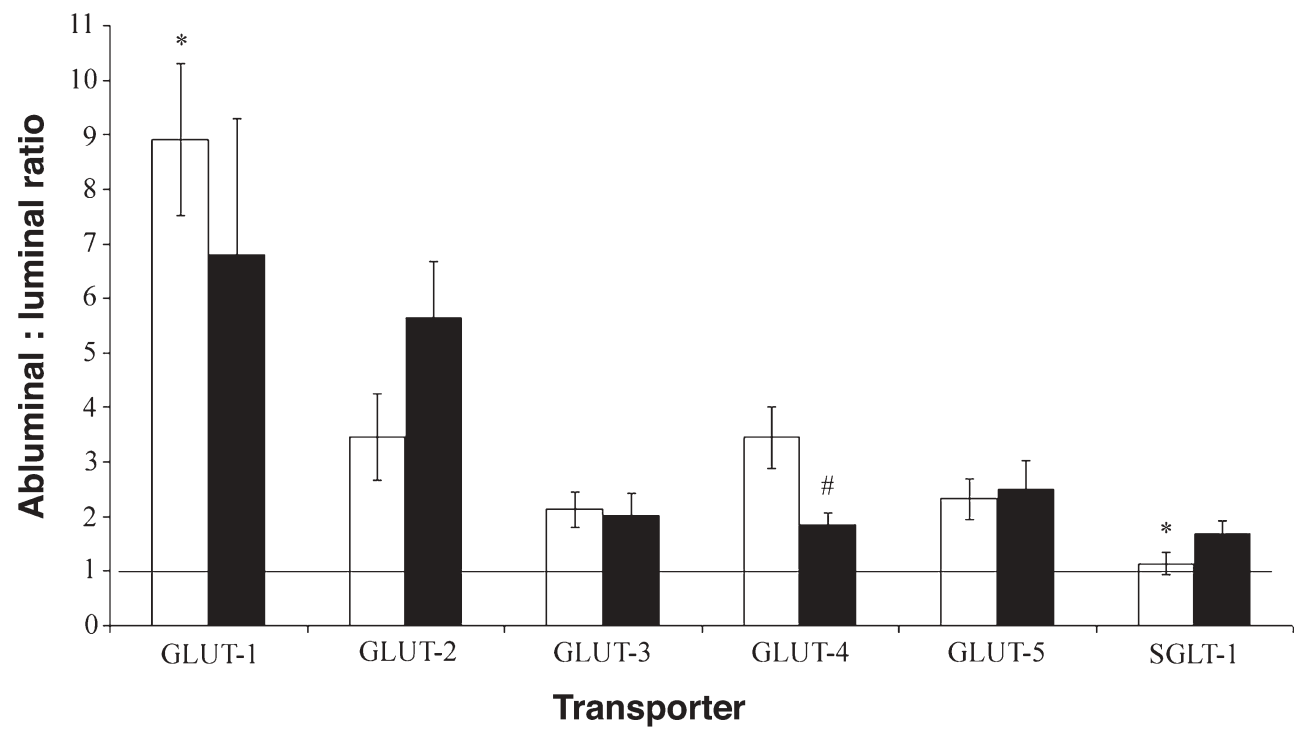

Fig. 5. Plot of the ratio of the number of abluminal : luminal voxels per cell (mean $\pm \mathrm{SE}$ ) for control (open bars) and diabetic (filled bars) animals (each bar is the average of seven cells from four rats). * Ratio is significantly different from the other control values; \# ratio is significantly different between the diabetic and the control values
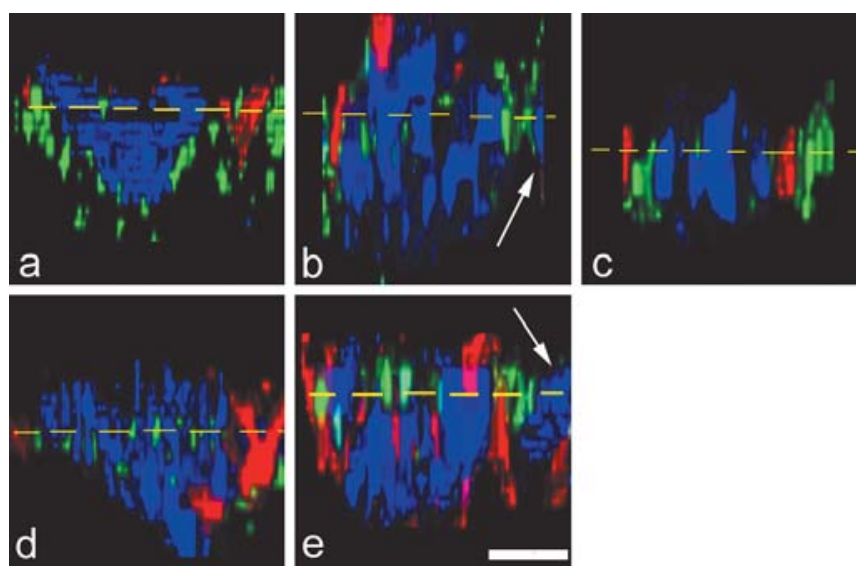

Fig. 6. Cross-sections of en face septal artery endothelial cells labelled with antibodies for a glucose transporter (green) and VE-cadherin (red). The nuclei were stained with DAPI (blue). The cross-sections are $0.5 \mu \mathrm{m}$ thick and the scale bar is $2 \mu \mathrm{m}$. The dashed line indicates where the cross-sections were divided into luminal (top) and abluminal (bottom) sections. a. GLUT-2; b. GLUT-3; c. GLUT-4; d. GLUT-5; e. SGLT-1

Effect of long-term hyperglycaemia. Sustained hyperglycaemia (8 weeks) produced significant reductions in the total number of voxels labelled for GLUT-1, 3, 4 and 5, but the number of voxels labelled for GLUT2 was dramatically increased (Fig. 7). These changes did not significantly affect the abluminal : luminal distributions of any of the transporters except GLUT4 , where there was a significant shift towards the luminal side of the cell (Fig. 5) in spite of an $80 \%$ reduction in the total number of illuminated voxels (Fig. 7).

\section{Discussion}

Our principal findings are that the endothelial cells of the septal artery express GLUT-1 to 5 and SGLT-1, and that long-term hyperglycaemia induced by STZ had a profound effect on their expression. We observed a downregulation of GLUT-1, 3, 4, and 5, and a three-fold increase of GLUT-2 in the endothelial cells of STZ-diabetic rats. We examined an en face endothelial preparation because endothelial cell structure is maintained by the surrounding environment and by interactions with neighbouring cells $[10,28]$. In particular, endothelial cells, when cultured, have a tendency to lose the ability to express most of the GLUT and SGLT isoforms [29, 30]. By studying the endothelium of freshly dissected vessels, we preserved the cellular architecture of the endothelial cells as close to the native state as possible. The endothelial markers allowed us to readily visualise the cells in the intact vessel, and the Ac-LDL uptake indicated that they remained viable throughout the dissection (Fig. 1).

Immunostaining. We have interpreted an increase or decrease in the number of voxels labelled for a given transporter as increases or decreases in that transporter's protein expression. We cannot draw any conclusions about the relative expression levels between the transporters as we do not know the affinity of the primary or secondary antibodies for their epitopes. The specificity of the antibodies used in these studies has been thoroughly tested. First, BLAST searches confirmed that the sequences of the epitopes recognised by the antibodies are unique to the proteins. Second, we obtained positive and negative controls for each antibody using immunohistochemistry in well- 


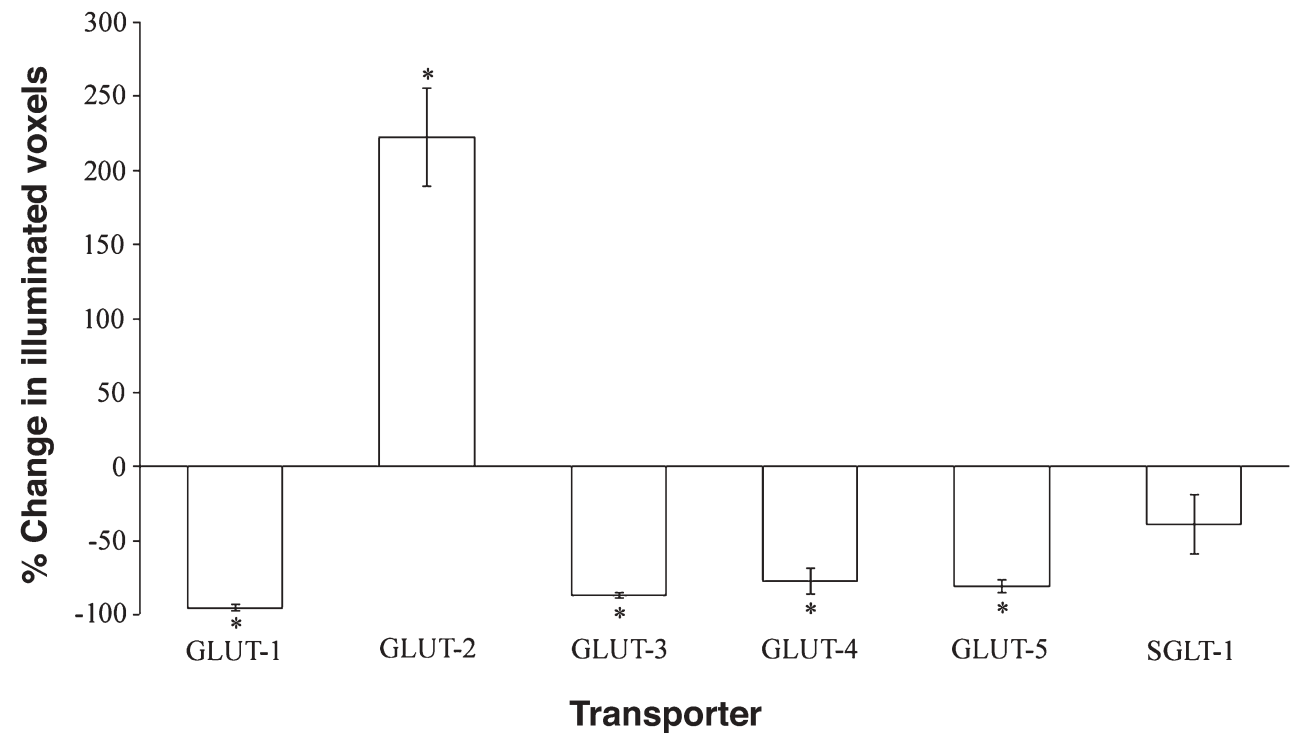

Fig. 7. Plot of the percentage change in the number of labelled voxels per cell (mean $\pm \mathrm{SE}$ ) in the diabetic animal compared with in the control animal. ${ }^{*} p<0.05$ vs control

characterised cells and tissues. Third, western blots produced single bands of the appropriate molecular weight for each of the GLUTs [31, 32, 33, 34, 35]. Fourth, control peptides for GLUT-3, 5 and SGLT blocked the labelling. Together, these results indicate that the antibodies are specific for each GLUT isoform.

All of the GLUTs and SGLT-1 were distributed in discrete clusters. This organised distribution may reflect the capacity of the transporters to target specific subcellular sites and tether or anchor to cytoskeletal proteins, as has been observed for GLUT-1 [36]. While most labelling surrounded the nucleus and the edge of the cells, a small amount seems to be located within the nucleus (Figs. 4c, 4d, 6b, 6d). A plane by plane analysis revealed that this labelling is located in deep folds of the nuclear envelope, typical for the nucleus of an endothelial cell [37], and constitutes perinuclear and not intranuclear labelling.

GLUT-1. Consistent with previous studies [6], we found GLUT-1 in endothelial cells. We also found that it is asymmetrically distributed, with a greater abundance on the abluminal side. A similar distribution of GLUT-1 has been previously reported in the blood-brain barrier [38, 39, 40], where GLUT-1 has long been considered the main glucose transporter [41]. The high affinity, intrinsic asymmetry (glucose extrusion from the cell can be 20 times faster than its uptake $[42,43])$ and high abluminal density of GLUT1 suggest that this transporter participates in the maintenance of constant transport of glucose from the cytosol of endothelial cells to the interstitial space in the vascular wall.
GLUT-2. To our knowledge, we are the first to report the presence of GLUT-2 in the endothelial cells of a small artery. A basolateral distribution of GLUT-2 has been found in epithelial cells of kidney proximal tubules and the small intestine [18, 44, 45], where it enables the rapid extrusion of accumulated intracellular glucose, facilitating its transfer to the interstitium. If transcellular glucose transport occurs across the endothelium of coronary arteries, then the low affinity/high capacity of GLUT-2 and its high abluminal density would contribute to the transfer of glucose from the blood to the cells of the vascular wall. Thus, GLUT-1 may be responsible for glucose extrusion at basal concentrations, while GLUT-2 could potentially protect endothelial cells from elevated intracellular glucose accumulation during brief periods of hyperglycaemia.

GLUT-3, 4, and 5. We also found that GLUT-3, 4 and 5 were present in these endothelial cells. Other groups have previously reported the presence of GLUT-3 [35, 46] and GLUT-5 [35] in brain endothelial cells. The presence of GLUT-4 has been previously reported in endothelial cells of the blood barrier (retinal and brain) $[29,47,48]$ and in fat and muscle capillary endothelial cells [49], while it was absent in cultured cardiac [50], cultured aortic [29], and human muscle capillary endothelial cells [51]. These contradictory findings could, in part, be explained by the heterogeneity found between endothelial cells of different vascular beds and vessels of different calibres, and by the fact that endothelial cells, when cultured, have a tendency to lose the ability to express most of the GLUT and SGLT isoforms $[29,30]$.

SGLT-1. We found SGLT in coronary endothelial cells. The presence of SGLT, also previously reported in bovine cortical artery endothelial cells [52, 53, 54], raises the question of its role in the cells of the vascular wall. Since a permanent $\mathrm{Na}^{+}$gradient is maintained 
between the blood and the cytosol of the cell, one would expect a constant activation of SGLT in the endothelial cells even during periods of low blood glucose. Nishizaki et al. have shown that low glucose levels enhance the activity of SGLT in bovine cortical artery endothelial cells [53]. Thus, the activity of SGLT-1 may be of greater importance during stresses such as hypoglycaemia in endothelial cells, in which case its unique capacity to transport glucose against its concentration gradient may serve the cells of the vascular wall during prolonged periods of starvation.

Other transporters. In addition to the GLUT isoforms that we studied, there are another seven known isoforms (GLUT-6 to 12) [9], at least two other isoforms of SGLT [55], and the proton-myoinositol symporter [9]. Antibodies to some of these transporters became available after this study was completed, and for this reason we have not examined their role in the vascular endothelial cell.

Cell junction labelling. A surprising result was the preferential localisation of all glucose transporter isoforms towards the edge of the cell, near the cell-to-cell junctions (Figs. 4, 5). In these regions of the cells, the luminal and abluminal membranes are at their closest apposition. This, combined with the preferential distribution of the GLUTs on the abluminal side, suggests that there could be transcellular transport of glucose through endothelial cells at their narrowest points. We cannot rule out the possibility of paracellular glucose transport, particularly given the discontinuous adherens junctions, which are characteristic of endothelia exposed to shear stress [27], and given that glucose transport across the capillaries in the microvasculature is thought to be almost exclusively paracellular [56]. Nevertheless, our results indicate that endothelial cells possess the molecular architecture to promote rapid transcellular transport of glucose to the cells of the vascular wall, and with SGLT-1, GLUT-1 and GLUT2 on the luminal side, to maintain transcellular transport across a wide range of glucose concentrations.

Effect of hyperglycaemia. Hyperglycaemia had profound effects on all of the GLUTs, significantly reducing the number of labelled voxels for all except GLUT-2, which was dramatically increased. The decrease in GLUT-1 staining is consistent with reports indicating that the expression of this transporter is downregulated both in rat heart endothelium following STZ-induced diabetes [31], and in bovine aortic endothelial cells exposed to hyperglycaemia for $48 \mathrm{~h}$ [57]. The latter was associated with an enhanced production of 12-hydroxyeicosatetraenoic acid (12HETE), which may downregulate the production of GLUT-1 and may decrease its maximal velocity. STZ treatment has been shown to increase the production of 12-HETE in rats [58]; thus, it may be responsible for the observed downregulation in this study. There are no reports of the effects of prolonged hyperglycaemia on the expression of GLUT-3, 4 and 5 in the endothelium, but our results indicate that their expression is also reduced. These changes, which would reduce glucose uptake, might be an effective strategy by which the endothelium could protect itself from hyperglycaemia, were it not for GLUT-2. We observed a three-fold increase in the number of voxels stained for GLUT-2 in STZ-treated rats (Fig. 7). This is the first report of its kind with regard to the endothelium, but our results are consistent with the dramatic increases in GLUT-2 expression seen in rat intestinal enterocytes [59] and kidney proximal tubule cells [60] in response to STZ-induced diabetes. The presence of GLUT-2, and its increase in diabetes, would be expected to have profound effects on the ability of the endothelial cell to regulate its glucose uptake.

STZ treatment is a well-established animal model of type 1 diabetes. It could be argued that the observed changes in the GLUT isoforms are due to the effect of the STZ toxin rather than to hyperglycaemia. Previous studies have shown that STZ toxicity is restricted to cells expressing GLUT-2 [61], and that its effect, either no change or a decrease in the level of GLUT-2 protein expression [62,63], is the opposite of that observed here. Although GLUT-2 may facilitate the transport of STZ in cells, it is not necessarily targeted by the toxin. Burkart et al. [62] identified NAD ${ }^{+}$ depletion caused by poly ADP-ribose polymerase (PARP) activation, as the metabolic event leading to cell death. The study went on to demonstrate that knock-out $\mathrm{PARP}^{-/-}$mice were completely resistant to the STZ toxin. The STZ-treated knock-out mice were normoglycaemic, maintained a normal level of secreted insulin, and preserved their islet ultrastructure. In addition, the level of GLUT-2 protein expression found in the islets was unaffected by STZ [62]. It is only following multiple doses of STZ (after three to five doses of $40 \mathrm{mg} \cdot \mathrm{kg}^{-1} \cdot \mathrm{day}^{-1}$ ) that Wang et al. observed a decrease in GLUT-2 protein levels in mouse pancreatic beta cells [63], which preceded the development of hyperglycaemia and beta cell destruction. In other tissues expressing GLUT-2 (liver, intestine and kidney proximal tubules), an increase in the protein level is observed following STZ-induced hyperglycaemia. This effect is reversed by insulin [64] or insulin-like growth factor [65], or is abolished by overnight fasting [60], indicating that the transporter upregulation is a direct effect of hyperglycaemia and/or hypoinsulinaemia. With these observations taken together, it is most likely that the increased level of GLUT-2 observed in our study is attributable to hyperglycaemia and/or hypoinsulinaemia rather than to any direct effect of the STZ toxin.

Intracellular glucose accumulation. Our results seem to indicate that the endothelial cells have a range of 
transporters that should protect them against accumulating intracellular glucose as well as an adaptive response to hyperglycaemia (a reduction in the expression of GLUT-1, 3, 4 and 5) that should reduce glucose uptake under these conditions. Why then do endothelial cells have a high susceptibility to glucose toxicity? Despite appearances, we think that the subcellular organisation of the GLUTs and the inability to downregulate GLUT-2 may be unfavourable for the cell exposed to hyperglycaemia, regardless of whether glucose transport through this endothelium is largely transcellular or paracellular. The high abluminal density of GLUT-2 may compromise the net extrusion rate of glucose on the abluminal side if the glucose concentration in the interstitial space remains elevated. This is likely to occur if the rate of glucose uptake by the smooth muscle cells is lower than the rate of extrusion by the endothelial cell, which is probable, given that smooth muscle cells are reported to downregulate glucose uptake far better than endothelial cells $[66,67]$. The high abluminal density of GLUT-2 increases the possibility of glucose reuptake down its concentration gradient from the abluminal surface of endothelial cells. The counterproductive increase in GLUT-2 expression, if this represents the production of functional protein, would exacerbate this problem, and may explain why endothelial cells are so susceptible to hyperglycaemic damage. If this hypothesis is correct, it follows that reducing the expression of GLUT-2 in the endothelial cell may have beneficial effects. In support of this, recent clinical trials using an inhibitor of PKC- $\beta$, which controls the transport of GLUT-2 to the membrane [68], have demonstrated a significant improvement in endothelial function that could be explained, in part, by a reduction of GLUT-2 trafficking [69].

Our results suggest that vascular endothelial cells are particularly susceptible to glucose toxicity due to their inability to decrease the expression of GLUT-2 during prolonged hyperglycaemia. Further studies will be required to determine the specific functional role of each transporter isoform.

Acknowledgements. The authors are grateful for the support of the Heart and Stroke Foundation of British Columbia and the Yukon, and the Canadian Institutes of Health Research. We thank R. Pederson and J. Martin for providing the streptozotocin and help with the injections, and K. Baimbridge for the primary neuron cultures. We are also grateful to $\mathrm{C}$. McIntosh for his critical reading of the manuscript and for valuable discussions.

\section{References}

1. Davis MJ, Hill MA (1999) Signaling mechanisms underlying the vascular myogenic response. Physiol Rev 79:387-423

2. Grundy SM, Benjamin IJ, Burke GL et al. (1999) Diabetes and cardiovascular disease: a statement for healthcare professionals from the American Heart Association. Circulation 100:1134-1146
3. Aronson D, Rayfield EJ (2002) How hyperglycemia promotes atherosclerosis: molecular mechanisms. Cardiovasc Diabetol 1:1

4. Brownlee M (2001) Biochemistry and molecular cell biology of diabetic complications. Nature 414:813-820

5. Sheetz MJ, King GL (2002) Molecular understanding of hyperglycemia's adverse effects for diabetic complications. JAMA 288:2579-2588

6. Mann GE, Yudilevich DL, Sobrevia L (2003) Regulation of amino acid and glucose transporters in endothelial and smooth muscle cells. Physiol Rev 83:183-252

7. Olson AL, Pessin JE (1996) Structure, function, and regulation of the mammalian facilitative glucose transporter gene family. Annu Rev Nutr 16:235-256

8. Barrett MP, Walmsley AR, Gould GW (1999) Structure and function of facilitative sugar transporters. Curr Opin Cell Biol 11:496-502

9. Joost HG, Thorens B (2001) The extended GLUT-family of sugar/polyol transport facilitators: nomenclature, sequence characteristics, and potential function of its novel members (review). Mol Membr Biol 18:247-256

10. Garlanda C, Dejana E (1997) Heterogeneity of endothelial cells. Specific markers. Arterioscler Thromb Vasc Biol 17:1193-1202

11. Ghitescu L, Robert M (2002) Diversity in unity: the biochemical composition of the endothelial cell surface varies between the vascular beds. Microsc Res Tech 57:381-389

12. Dan P, Cheung JC, Scriven DR, Moore ED (2003) Epitopedependent localization of estrogen receptor-alpha, but not beta, in en face arterial endothelium. Am J Physiol Heart Circ Physiol 284:H1295-H1306

13. Leach L, Clark P, Lampugnani MG, Arroyo AG, Dejana E, Firth JA (1993) Immunoelectron characterisation of the inter-endothelial junctions of human term placenta. J Cell Sci 104:1073-1081

14. Firth JA (2002) Endothelial barriers: from hypothetical pores to membrane proteins. J Anat 200:541-548

15. Farrell CL, Pardridge WM (1991) Blood-brain barrier glucose transporter is asymmetrically distributed on brain capillary endothelial lumenal and ablumenal membranes: an electron microscopic immunogold study. Proc Natl Acad Sci USA 88:5779-5783

16. Concha, II, Velasquez FV, Martinez JM et al. (1997) Human erythrocytes express GLUT5 and transport fructose. Blood 89:4190-4195

17. Sato Y, Ito T, Udaka N et al. (1996) Immunohistochemical localization of facilitated-diffusion glucose transporters in rat pancreatic islets. Tissue Cell 28:637-643

18. Thorens B (1996) Glucose transporters in the regulation of intestinal, renal, and liver glucose fluxes. Am J Physiol 270:G541-G553

19. Krebs C, Fernandes HB, Sheldon C, Raymond LA, Baimbridge KG (2003) Functional NMDA receptor subtype $2 \mathrm{~B}$ is expressed in astrocytes after ischemia in vivo and anoxia in vitro. J Neurosci 23:3364-3372

20. Abdel-Hamid KM, Baimbridge KG (1997) The effects of artificial calcium buffers on calcium responses and glutamate-mediated excitotoxicity in cultured hippocampal neurons. Neuroscience 81:673-687

21. Moore ED, Etter EF, Philipson KD et al. (1993) Coupling of the $\mathrm{Na}+\mathrm{Ca} 2+$ exchanger, $\mathrm{Na}+/ \mathrm{K}+$ pump and sarcoplasmic reticulum in smooth muscle. Nature 365:657-660

22. Carrington WA, Lynch RM, Moore ED, Isenberg G, Fogarty KE, Fay FS (1995) Superresolution three-dimensional images of fluorescence in cells with minimal light exposure. Science 268:1483-1487 
23. Galbraith CG, Skalak R, Chien S (1998) Shear stress induces spatial reorganization of the endothelial cell cytoskeleton. Cell Motil Cytoskeleton 40:317-330

24. Netland PA, Zetter BR, Via DP, Voyta JC (1985) In situ labelling of vascular endothelium with fluorescent acetylated low density lipoprotein. Histochem J 17:1309-1320

25. Leino RL, Gerhart DZ, van Bueren AM, McCall AL, Drewes LR (1997) Ultrastructural localization of GLUT 1 and GLUT 3 glucose transporters in rat brain. J Neurosci Res 49:617-626

26. Blakemore SJ, Aledo JC, James J, Campbell FC, Lucocq JM, Hundal HS (1995) The GLUT5 hexose transporter is also localized to the basolateral membrane of the human jejunum. Biochem J 309:7-12

27. Noria S, Cowan DB, Gotlieb AI, Langille BL (1999) Transient and steady-state effects of shear stress on endothelial cell adherens junctions. Circ Res 85:504-514

28. Redmond EM, Cahill PA, Sitzmann JV (1995) Perfused transcapillary smooth muscle and endothelial cell coculture-a novel in vitro model. In Vitro Cell Dev Biol Anim 31:601-609

29. McCall AL, van Bueren AM, Huang L, Stenbit A, Celnik E, Charron MJ (1997) Forebrain endothelium expresses GLUT4, the insulin-responsive glucose transporter. Brain Res 744:318-326

30. Mamchaoui K, Makhloufi Y, Saumon G (2002) Glucose transporter gene expression in freshly isolated and cultured rat pneumocytes. Acta Physiol Scand 175:19-24

31. Hirsch B, Rosen P (1999) Diabetes mellitus induces long lasting changes in the glucose transporter of rat heart endothelial cells. Horm Metab Res 31:645-652

32. Thorens B, Sarkar HK, Kaback HR, Lodish HF (1988) Cloning and functional expression in bacteria of a novel glucose transporter present in liver, intestine, kidney, and beta-pancreatic islet cells. Cell 55:281-290

33. Gould GW, Brant AM, Kahn BB, Shepherd PR, McCoid SC, Gibbs EM (1992) Expression of the brain-type glucose transporter is restricted to brain and neuronal cells in mice. Diabetologia 35:304-309

34. James DE, Strube M, Mueckler M (1989) Molecular cloning and characterization of an insulin-regulatable glucose transporter. Nature 338:83-87

35. Mantych GJ, James DE, Devaskar SU (1993) Jejunal/ kidney glucose transporter isoform (Glut-5) is expressed in the human blood-brain barrier. Endocrinology 132:35-40

36. Bunn RC, Jensen MA, Reed BC (1999) Protein interactions with the glucose transporter binding protein GLUT1CBP that provide a link between GLUT1 and the cytoskeleton. Mol Biol Cell 10:819-832

37. Woolf N (1982) Pathology of atherosclerosis. Butterworths and Co., London

38. Dobrogowska DH, Vorbrodt AW (1999) Quantitative immunocytochemical study of blood-brain barrier glucose transporter (GLUT-1) in four regions of mouse brain. J Histochem Cytochem 47:1021-1030

39. Cornford EM, Hyman S, Cornford ME, Damian RT, Raleigh MJ (1998) A single glucose transporter configuration in normal primate brain endothelium: comparison with resected human brain. J Neuropathol Exp Neurol 57:699-713

40. Bolz S, Farrell CL, Dietz K, Wolburg H (1996) Subcellular distribution of glucose transporter (GLUT-1) during development of the blood-brain barrier in rats. Cell Tissue Res 284:355-365

41. Pardridge WM, Boado RJ, Farrell CR (1990) Brain-type glucose transporter (GLUT-1) is selectively localized to the blood-brain barrier. Studies with quantitative western blotting and in situ hybridization. J Biol Chem 265:18035-18040
42. Kinne RK (1997) Endothelial and epithelial cells: general principles of selective vectorial transport. Int $\mathbf{J}$ Microcirc Clin Exp 17:223-230

43. Gould GW, Seatter MJ (1997) Introduction to the facilitative glucose transporter family. In: Gould GW (ed) Facilitative glucose transporters. R.G. Landes, Austin, New York, pp 1-37

44. Wallner EI, Wada J, Tramonti G, Lin S, Kanwar YS (2001) Status of glucose transporters in the mammalian kidney and renal development. Ren Fail 23:301-310

45. Takata K (1996) Glucose transporters in the transepithelial transport of glucose. J Electron Microsc (Tokyo) 45:275-284

46. Urabe T, Hattori N, Nagamatsu S, Sawa H, Mizuno Y (1996) Expression of glucose transporters in rat brain following transient focal ischemic injury. $J$ Neurochem 67:265-271

47. King GL, Buzney SM, Kahn CR et al. (1983) Differential responsiveness to insulin of endothelial and support cells from micro- and macrovessels. J Clin Invest 71:974-979

48. Frank HJ, Pardridge WM (1981) A direct in vitro demonstration of insulin binding to isolated brain microvessels. Diabetes 30:757-761

49. Vilaro S, Palacin M, Pilch PF, Testar X, Zorzano A (1989) Expression of an insulin-regulatable glucose carrier in muscle and fat endothelial cells. Nature 342:798-800

50. Thomas J, Linssen M, van der Vusse GJ et al. (1995) Acute stimulation of glucose transport by histamine in cardiac microvascular endothelial cells. Biochim Biophys Acta 1268:88-96

51. Friedman JE, Dudek RW, Whitehead DS et al. (1991) Immunolocalization of glucose transporter GLUT4 within human skeletal muscle. Diabetes 40:150-154

52. Nishizaki T, Kammesheidt A, Sumikawa K, Asada T, Okada Y (1995) A sodium- and energy-dependent glucose transporter with similarities to SGLT1-2 is expressed in bovine cortical vessels. Neurosci Res 22:13-22

53. Nishizaki T, Matsuoka T (1998) Low glucose enhances $\mathrm{Na} /$ glucose transport in bovine brain artery endothelial cells. Stroke 29:844-849

54. Matsuoka T, Nishizaki T, Kisby GE (1998) Na+-dependent and phlorizin-inhibitable transport of glucose and cycasin in brain endothelial cells. J Neurochem 70:772-777

55. Wright EM (2001) Renal $\mathrm{Na}(+)$-glucose cotransporters. Am J Physiol Renal Physiol 280:F10-F18

56. Michel CC, Curry FE (1999) Microvascular permeability. Physiol Rev 79:703-761

57. Alpert E, Gruzman A, Totary H, Kaiser N, Reich R, Sasson S (2002) A natural protective mechanism against hyperglycaemia in vascular endothelial and smooth-muscle cells: role of glucose and 12-hydroxyeicosatetraenoic acid. Biochem J 362:413-422

58. Antonipillai I, Jost-Vu E, Natarajan R, Nadler J, Horton R (1995) Renin response to 12-hydroxyeicosatetraenoic acid is increased in diabetic rats. Diabetes 44:321-325

59. Corpe CP, Basaleh MM, Affleck J, Gould G, Jess TJ, Kellett GL (1996) The regulation of GLUT5 and GLUT2 activity in the adaptation of intestinal brush-border fructose transport in diabetes. Pflugers Arch 432:192-201

60. Marks J, Carvou NJ, Debnam ES, Srai SK, Unwin RJ (2003) Diabetes increases facilitative glucose uptake and GLUT2 expression at the rat proximal tubule brush border membrane. J Physiol 553:137-145

61. Schnedl WJ, Ferber S, Johnson JH, Newgard CB (1994) STZ transport and cytotoxicity. Specific enhancement in GLUT2-expressing cells. Diabetes 43:1326-1333

62. Burkart V, Wang ZQ, Radons J et al. (1999) Mice lacking the poly(ADP-ribose) polymerase gene are resistant to pan- 
creatic beta-cell destruction and diabetes development induced by streptozocin. Nat Med 5:314-319

63. Wang Z, Gleichmann H (1998) GLUT2 in pancreatic islets: crucial target molecule in diabetes induced with multiple low doses of streptozotocin in mice. Diabetes 47:50-56

64. Thulesen J, Orskov C, Holst JJ, Poulsen SS (1997) Shortterm insulin treatment prevents the diabetogenic action of streptozotocin in rats. Endocrinology 138:62-68

65. Asada T, Takakura S, Ogawa T, Iwai M, Kobayashi M (1998) Overexpression of glucose transporter protein 5 in sciatic nerve of streptozotocin-induced diabetic rats. Neurosci Lett 252:111-114

66. Vinals F, Gross A, Testar X, Palacin M, Rosen P, Zorzano A (1999) High glucose concentrations inhibit glucose phosphorylation, but not glucose transport, in human endothelial cells. Biochim Biophys Acta 1450:119-129

67. Howard RL (1996) Down-regulation of glucose transport by elevated extracellular glucose concentrations in cultured rat aortic smooth muscle cells does not normalize intracellular glucose concentrations. J Lab Clin Med 127:504-515

68. Helliwell PA, Richardson M, Affleck J, Kellett GL (2000) Stimulation of fructose transport across the intestinal brush-border membrane by PMA is mediated by GLUT2 and dynamically regulated by protein kinase C. Biochem J 350:149-154

69. Beckman JA, Goldfine AB, Gordon MB, Garrett LA, Creager MA (2002) Inhibition of protein kinase C-beta prevents impaired endothelium-dependent vasodilation caused by hyperglycemia in humans. Circ Res 90:107-111 